\title{
Effects of regulated deficit irrigation on soil salinity, physiological processes and fruit quality of gray jujube under desert conditions
}

\author{
Zhipeng Liu' ${ }^{1}$, Chengli Zhu ${ }^{1}$, Shuyu $\mathrm{Wu}^{1}$, Weihua Guo ${ }^{1}$, Yitikaer Abudushalamu ${ }^{2}$, Xiyun Jiao ${ }^{1,3}$, \\ Shipei Gao ${ }^{4}$, Jie Wang ${ }^{5}$ \\ (1. College of Agricultural Engineering, Hohai University, Nanjing 210098, China; \\ 2. College of Hydraulic and Civil Engineering, Xinjiang Agricultural University, Urumqi 830052, China; \\ 3. State Key Laboratory of Hydrology-Water Resources and Hydraulic Engineering, Hohai University, Nanjing 210098, China; \\ 4. Hydraulic Research Institute of Jiangsu Province, Nanjing 210017, China; \\ 5. Development Center for Science and Technology of Rural Water Resources of Jiangsu Province, Nanjing 210029, China)
}

\begin{abstract}
Regulated deficit irrigation (RDI) was applied to gray jujube trees in an oasis region, to determine the effects of this irrigation system on soil salinity, gray jujube physiological processes, fruit yield, and fruit quality. Treatments consisted of severe, moderate and low deficit irrigation (irrigated with $85 \%, 70 \%$ and $55 \%$ of CK, respectively) at the flowering stage to fruit set stage. During the other growth stages, all treatments were irrigated with $80 \%$ of pan evaporation, which was the same as that in control. The results indicated that soil salinity was enhanced during the periods of water stress, but the high value of soil salinity declined by $3.48 \%-37.27 \%$, at each depth, after irrigation was resumed. RDI caused a decline in the photosynthetic rate, transpiration rate, and stomatal conductance, but enhanced the water use efficiency of the leaves. However, the leaf photosynthetic rate was effectively enhanced after the recovery of irrigation, especially in the moderate deficit irrigation treatment, which exceeded the control. This led to an improved fruit yield, which was $9.57 \%$ higher than that of the control. The deficit treatments caused a significant increase in the soluble solid content, soluble sugar content, single fruit weight and sugar/acid ratio. Enhanced vitamin C content, resulting from deficit treatments, has also been observed in the gray jujube. Therefore, this research shows that RDI provides some benefits in the production of gray jujube trees in desert conditions.
\end{abstract}

Keywords: regulated deficit irrigation, soil salinity, gray jujube, water use efficiency, photosynthetic rate, transpiration rate, stomatal conductance, soluble solid content, sugar/acid ratio

DOI: $10.25165 /$ j.ijabe.20191203.4262

Citation: Liu Z P, Zhu C L, Wu S Y, Guo W H, Abudushalamu Y, Jiao X Y, et al. Effects of regulated deficit irrigation on soil salinity, physiological processes and fruit quality of gray jujube under desert conditions. Int J Agric \& Biol Eng, 2019; 12(3): $52-59$.

\section{Introduction}

Jujube (Zizyphus jujube Mill.), originally from China, has more than 700 cultivars and a history of over 4000 years ${ }^{[1,2]}$. Jujube fruit has a high nutritional value and a long history being used as a medicinal remedy ${ }^{[3-5]}$. Xinjiang is one of the main jujube production regions in $\mathrm{China}^{[6]}$. In 2015 , the planting area of jujube reached $495548 \mathrm{hm}^{2}$, while $971783 \mathrm{hm}^{2}$ fruit trees were planted $^{[7]}$, and the yield of jujube fruits was $3054270 \mathrm{t}$. The jujube is primarily cultivated in the oases around the Taklamakan desert, where water resources face severe shortages and irrigation is

Received date: 2018-03-25 Accepted date: 2019-04-10

Biographies: Zhipeng Liu, PhD candidate, research interests: Theory and technology of water-saving irrigation, Email: 1zp15251770703@hhu.edu.cn; Shuyu Wu, PhD candidate, research interests: agricultural water and soil resources management, Email: wushuyu@hhu.edu.cn; Weihua Guo, PhD, research interests: agricultural water and soil resources management, Email: guoweihuaaza@aliyun.com; Yitikaer Abudushalamu, Master candidate, research interests: irrigation and drainage, Email: 446798808@qq.com; Xiyun Jiao, $\mathrm{PhD}$, Professor, research interests: Theory and technology of water-saving irrigation, Email: xyjiao@hhu.edu.cn; Shipei Gao, Master, research interests: irrigation and drainage, Email: 476845942@qq.com; Jie Wang, Master, research interests: irrigation and drainage, Email: 332155763@qq.com.

*Corresponding author: Chengli Zhu, PhD, Professor, College of Agricultural Engineering, Hohai University, Nanjing 210098, Jiangsu, China. Tel: +86-13951808509; Email: clz@hhu.edu.cn. needed for high yields and good quality. However, jujube planted with inappropriate irrigation may result in a waste of water resources and a poor fruit quality ${ }^{[8]}$. Therefore, it is extremely important for water irrigation to be efficient, especially in jujube orchards, which located on the rim of desert areas.

Regulated deficit irrigation (RDI), in which water capacity is below full, is a valuable method to cope with water shortages and increase the utilization efficiency of irrigation in arid regions ${ }^{[9,10]}$. A substantial amount of researches for RDI have been conducted on various crops, including maize, pear, tomato, grape, almond, squash, and citrus ${ }^{[11-17]}$. Wu et al. ${ }^{[14]}$ found that deficit treatments could efficiently restrict vegetative growth and obtain bigger fruit sizes and higher yields. Akhtar et al. ${ }^{[12]}$ reported that the application of water stress and biochar was good for conserving water and enhancing the productivity and quality of tomato under limited fresh-water resources. El-Mageed et al. ${ }^{[11]}$ indicated that using deficit drip irrigation for squash cultivation, $15 \%$ water can be saved and improved yield and water use efficiency. It has been observed that using deficit irrigation not only reduces the agricultural water use, but also increases the fruit yield, product quality, water use efficiency and farmers' profits ${ }^{[8,18-21]}$.

Deficit irrigation applied to jujube trees have been reported by many researchers ${ }^{[8,22-24]}$. Recovery irrigation, after a period of RDI, significantly increases the leaf photosynthesis rate $\left(P_{\mathrm{n}}\right)$ of fruit trees. This compensatory effect occurred after experiencing 
water stress, with similar results found in other studies ${ }^{[16,25,26]}$. Deficit treatments applied during the growth stages of pear-jujube trees led to $P_{\mathrm{n}}$ with a significant compensatory effect, increased fruit yield and water use efficiency $\left(W U E_{\mathrm{L}}\right)$ by $13.2 \%-31.9 \%$ and $31.4 \%-42.2 \%$, respectively. Additionally, pear- jujube trees had enhanced fruit firmness, soluble solid content, sugar/acid ratio and vitamin C (VC) content ${ }^{[8,22]}$. Jujube was clearly sensitive to water deficit during the fruit maturation stage, and exhibited no direct relationships between the turgor and fruit size ${ }^{[23]}$. In contrast, Ma et al. ${ }^{[24]}$ reported that a serious water deficit during the fruit maturation stage enhanced the organic acid and soluble solid content, but had a slight adverse impact on the average fruit weight, $\mathrm{VC}$, and soluble albumen.

Moreover, photosynthetic analysis is effective for understanding how deficit irrigation affects leaf physiological parameters. The stomatal closure is responsible for reducing water loss under water stress by inducing a decline in the transpiration and photosynthetic rates ${ }^{[27-29]}$. Zhao et al. ${ }^{[26]}$ indicated that during the water deficit period, the leaf stomatal conductance, transpiration rate and photosynthetic rate decreased, but the leaf water use efficiency $\left(W U E_{\mathrm{L}}, P_{\mathrm{n}} / T_{\mathrm{r}}\right)$ increased. Cui et al. ${ }^{[22]}$ and Pérez-Pérez et al. ${ }^{[25]}$ found that upon resuming irrigation after water stress, the stomatal conductance, transpiration rate and photosynthetic rate of trees enhanced significantly and surpassed the control values. Although some of the previous experiments on jujube trees have confirmed the positive effects of deficit irrigation, it is needed to understand how deficit irrigation affects jujube yield and quality by monitoring the photosynthetic processes of the leaves.

The use of deficit irrigation may result in the accumulation of soil salt, which aggravates soil salinization in arid areas ${ }^{[6,30,31]}$. Furthermore, the changes in the soil salinity and fraction of field-wide leaching were linearly and negatively correlated, indicating that soil salinization increased with a decreasing leaching fraction ${ }^{[32]}$. Thus, the appropriate irrigation technique is useful to balance the evapotranspiration and leaching fraction. A water conservation strategy that saving up to $25 \%$ of irrigation water will keep the soil healthier under both drained and undrained conditions where good-quality canal water is available ${ }^{[33]}$. However, research on the effects of deficit irrigation on soil salinization is scarce in oases.

This study aimed on the following investigations: (1) the distribution and build-up of salinity within adult jujube root zones, where drip irrigation with different water shortages is applied; (2) how RDI affects the leaf photosynthetic rate $\left(P_{\mathrm{n}}\right)$, transpiration rate $\left(T_{\mathrm{r}}\right)$, stomatal conductance $\left(g_{\mathrm{s}}\right)$ and water use efficiency $\left(W U E_{\mathrm{L}}\right)$ of jujube trees; and (3) the responses of fruit yield and quality to different water stress levels.

\section{Materials and methods}

\subsection{Experimental materials and design}

The experiment was conducted in a gray jujube orchard of

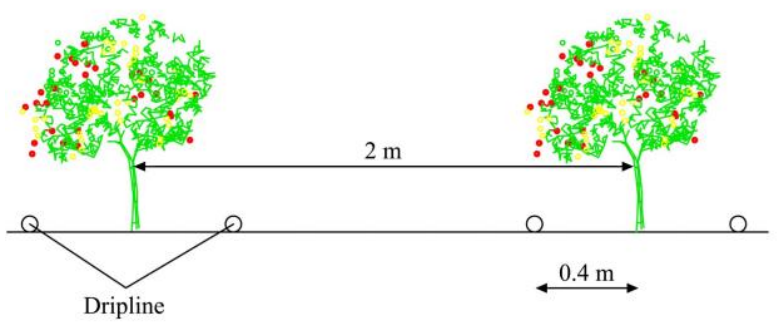

Qiemo County 38 Regiment, Bayingolin, Xinjiang Region $\left(37^{\circ} 47^{\prime} \mathrm{N}, 84^{\circ} 08^{\prime} \mathrm{E}\right)$, which is in the south rim of the Taklamakan desert. It has a continental, arid climate with the mean annual temperature of $10.4^{\circ} \mathrm{C}$, the mean annual precipitation of $18.1 \mathrm{~mm}$ and the mean annual evaporation of $2824 \mathrm{~mm}$. The gray jujube plants start budding in the middle of April, with fruits harvesting in late October. The monthly precipitation, relative humidity, and temperature during the study period are provided in Table 1 .

Table 1 Air temperature, relative humidity, and precipitation of the study site

\begin{tabular}{cccccc}
\hline Month & $\begin{array}{c}\text { Mean } \\
\text { temperature } \\
/{ }^{\circ} \mathrm{C}\end{array}$ & $\begin{array}{c}\text { Maximum } \\
\text { temperature } \\
/{ }^{\circ} \mathrm{C}\end{array}$ & $\begin{array}{c}\text { Minimum } \\
\text { temperature } \\
/{ }^{\circ} \mathrm{C}\end{array}$ & $\begin{array}{c}\text { Relative } \\
\text { humidity } \\
/ \%\end{array}$ & $\begin{array}{c}\text { Precipitation } \\
/ \mathrm{mm}\end{array}$ \\
\hline April & 16.1 & 32.7 & 1.5 & 26.2 & 0.0 \\
May & 21.9 & 36.0 & 1.8 & 22.0 & 2.0 \\
June & 23.8 & 38.0 & 8.6 & 36.5 & 5.4 \\
July & 26.6 & 40.4 & 13.2 & 39.6 & 1.0 \\
August & 24.2 & 37.5 & 11.5 & 38.4 & 0.4 \\
September & 20.5 & 33.7 & 6.2 & 35.7 & 0.0 \\
October & 10.2 & 27.4 & -5.3 & 35.5 & 0.2 \\
\hline
\end{tabular}

Note: The meteorological data of the experiment site was measured in 2017.

The materials used in the experiment were 7-year-old gray jujube trees, which were planted with distances of $2 \mathrm{~m}$ between rows and $1 \mathrm{~m}$ between trees in a row $\left(5000\right.$ tree $\left./ \mathrm{hm}^{2}\right)$. Two driplines (two emitters with $0.3 \mathrm{~m}$ between intervals; $3.2 \mathrm{~L} / \mathrm{h}$ for each emitter), located $0.4 \mathrm{~m}$ away from the tree row (Figure 1), provided water on both sides of the trees. The soil is sand (USAD). A summary of the soil properties is presented in Table 2. The roots of the 7-year-old gray jujube trees occurred mainly at depths of 0-40 cm. The groundwater has a depth of $1.8 \mathrm{~m}$ with high salinity $(3.17 \mathrm{~g} / \mathrm{L})$. The irrigation water comes from the snow of Kunlun Mountain ( $0.47 \mathrm{~g} / \mathrm{L})$.

The experiment involved 3 irrigation treatments and a control treatment (CK, local irrigation water quantity), in which the control was irrigated with a pan evaporation $\left(E_{\mathrm{p}}\right)$ of $80 \%$ during the entire growth season ${ }^{[14,26,34]}$. The low (LD), moderate (MD) and severe (SD) RDI treatments were irrigated with $85 \%, 70 \%$ and $55 \%$ of $\mathrm{CK}$ during the flowering to fruit set stage, respectively, and irrigated with an $E_{\mathrm{p}}$ of $80 \%$ during the other growth stages (Table 3 ). The experimental design was a completely randomized plot, with three replicates per treatment.

The individual plot area was $60 \mathrm{~m}^{2}$, which consisted of 30 gray jujube trees in three rows. All treatments were supplied with identical application rates of urea $\mathrm{N}$ fertilizer $200 \mathrm{~kg} / \mathrm{hm}^{2}$, calcium superphosphate Ca fertilizer $250 \mathrm{~kg} / \mathrm{hm}^{2}$, and monopotassium phosphate K fertilizer $250 \mathrm{~kg} / \mathrm{hm}^{2}$. One half of the $\mathrm{N}$ and all the $\mathrm{Ca}$ fertilizer were distributed evenly and incorporated into the top $20 \mathrm{~cm}$ of the soil before the budding stage. The remaining half of the $\mathrm{N}$ and all the $\mathrm{K}$ fertilizer were applied throughout the entire growth season.

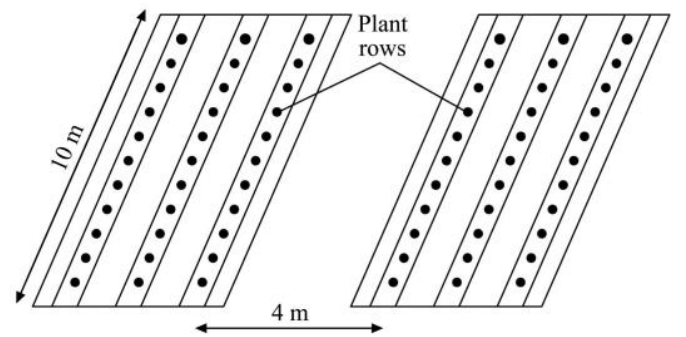

Figure 1 Field layout of the experiment and drip lines 
Table 2 Soil properties at the experimental site

\begin{tabular}{lcccc}
\hline \multirow{2}{*}{ Soil properties } & \multicolumn{4}{c}{ Soil depth/cm } \\
\cline { 2 - 5 } & $0-20$ & $20-40$ & $40-60$ & $60-80$ \\
\hline Sand/\% & 86.60 & 85.29 & 87.00 & 87.04 \\
Silt/\% & 10.32 & 11.65 & 9.97 & 9.85 \\
Cla/\% & 3.08 & 3.06 & 3.03 & 3.11 \\
Bulk density/g. $\mathrm{cm}^{-3}$ & 1.46 & 1.46 & 1.49 & 1.48 \\
Organic matter/\% & 9.54 & 9.70 & 10.04 & 9.69 \\
Moisture data/\% & 6.22 & 5.33 & 5.69 & 8.17 \\
\hline Note: Initial field-measured data from the experimental site.
\end{tabular}

Table 3 Accumulated pan evaporation and water irrigation for each treatment for gray jujube

\begin{tabular}{cccccc}
\hline Date & Pan evaporation/mm & $\mathrm{CK} / \mathrm{mm}$ & $\mathrm{LD} / \mathrm{mm}$ & $\mathrm{MD} / \mathrm{mm}$ & $\mathrm{SD} / \mathrm{mm}$ \\
\hline Apr 24 & & 60.0 & 60.0 & 60.0 & 60.0 \\
May 2 & 84.6 & 67.7 & 67.7 & 67.7 & 67.7 \\
May 10 & 87.4 & 69.9 & 69.9 & 69.9 & 69.9 \\
May 18 & 102.4 & 81.9 & 81.9 & 81.9 & 81.9 \\
May 26 & 102.7 & 82.2 & 82.2 & 82.2 & 82.2 \\
Jun 4 & 115.1 & 92.1 & 92.1 & 92.1 & 92.1 \\
Jun 10 & 84.5 & 67.6 & 57.5 & 47.3 & 37.2 \\
Jun 16 & 84.4 & 67.5 & 57.4 & 47.3 & 37.1 \\
Jun 22 & 81.1 & 64.9 & 55.1 & 45.4 & 35.7 \\
Ju1 2 & 145.2 & 116.2 & 98.7 & 81.3 & 63.9 \\
Ju1 9 & 88.9 & 71.1 & 60.5 & 49.8 & 39.1 \\
Jul 16 & 104.0 & 83.2 & 70.7 & 58.2 & 45.8 \\
Jul 23 & 86.9 & 69.5 & 59.1 & 48.7 & 38.2 \\
Jul 30 & 94.2 & 75.4 & 75.4 & 75.4 & 75.4 \\
Aug 9 & 121.5 & 97.2 & 97.2 & 97.2 & 97.2 \\
Aug 18 & 81.8 & 65.4 & 65.4 & 65.4 & 65.4 \\
\hline Not Pan & & & & &
\end{tabular}

Note: Pan evaporation was calculated from the day of the last irrigation to one day before the next irrigation.

\subsection{Measurements}

\subsubsection{Measurement of the soil salt contents}

The irrigation date and quantity were recorded throughout the entire growth stage per replication per treatment. The soil samples were taken at depths of $0-20 \mathrm{~cm}, 20-40 \mathrm{~cm}, 40-60 \mathrm{~cm}$ and $60-80 \mathrm{~cm}$ from the soil surface by the soil auger before irrigation (June 9, June 15, June 21, July 1, July 8, July 15, July 22, July 29, August 8, and August 17). A digital conductivity instrument (FE30K Plus, Mettler Toledo Corporation, China) was used to measure the electrical conductivity of 1:5 soil-water leachate $\left(E C_{1: 5}\right)$.

2.2.2 Measurements of the physiological parameters

Physiological parameters, including the leaf photosynthetic rate $\left(P_{\mathrm{n}}\right)$, transpiration rate $\left(T_{\mathrm{r}}\right)$, and stomatal conductance $\left(g_{\mathrm{s}}\right)$, were measured with a photosynthesis system (LI-6400XT, LI-COR, USA) under a natural temperature and relative humidity during GMT 11:00 am-12:30 pm, one day before the deficit water irrigation (June 9, June 15, July 1, July 22, August 8, and August 17). The light intensity was set at $1500 \mu \mathrm{mol} / \mathrm{m}^{2} \cdot \mathrm{s}$, which was provided by a $6400-02 B$ LED light source. Three sunlit, healthy leaves, in different directions, were selected and labeled according to a completely randomized design in each replicate ${ }^{[13,22,26]}$. The same leaves were measured through the flowering to fruit set and fruit maturation stages. Then, the $W U E_{\mathrm{L}}$ was calculated.

\subsubsection{Fruit yield and quality measurements}

Three trees per replication per treatment were harvested by hand, graded according to size and weighed using an electronic scale on October 30. Sixty fruits per treatment were randomly sampled and the single fruit weight and edible rate were measured. Then, quality indices were determined on the jujube. The fruit total organic sugar was measured with the anthrone method by using a spectrophotometer (UV1900PCS, Shanghai Analytical Instrument Co. Ltd., China). The acid content was measured with the $\mathrm{NaOH}$ titration method, the vitamin $\mathrm{C}$ content was measured using the 2,6-dichloroindophenol titration method, and soluble solids were measured with a portable digital refractometer (LB92T, Guangzhou Suwei Electronic Technology Co. Ltd, China). These analyses were performed in triplicate for each treatment.

2.2.4 Meteorological measurements

Daily meteorological data, such as the air temperature, atmospheric pressure, relative humidity, wind speed, and precipitation, were recorded by automatic weather stations (CAWS600, China Huayun Group Corporation, China) which were installed $2 \mathrm{~km}$ from the experimental field. The monthly values of precipitation, mean humidity, and temperature from the budding to harvest periods are presented in Table 1.

2.2.5 Statistical analysis

An analysis of variance (ANOVA) and correlation analysis were performed using statistical analysis software (SPSS 20.0, International Business Machines Corporation (IBM), USA). The means of each treatment were compared for significant differences using the Duncan's multiple range test at a significance level of $P_{0.05}$.

\section{Results}

\subsection{Soil salinity}

Among all the treatments, there were no significant differences between the average $E C_{1: 5}$ values at the different depths prior to RDI (Figure 2a-d). It was clear that the application of RDI enhanced the soil salinity and increased the risk of secondary salinization of the soil in desert conditions. In the $0-100 \mathrm{~cm}$ soil layer, the $E C_{1: 5}$ of the $\mathrm{LD}, \mathrm{MD}$, and $\mathrm{SD}$ treatments declined by $3.49 \%-10.29 \%, 8.50 \%-10.94 \%$, and $8.65 \%-16.85 \%$, respectively, after the irrigation resumed. It can be concluded that the decline of $E C_{1: 5}$ had a positive relationship with the degree of water deficit.

In the $0-20 \mathrm{~cm}$ soil layer, the average $E C_{1: 5}$ values of $L D, M D$ and SD increased to $145.27,192.08$ and $293.73 \mu \mathrm{s} / \mathrm{cm}$, respectively on July 29. This was an increase of $19.70 \%, 37.96 \%$, and $91.19 \%$, respectively compared with the $E C_{1: 5}$ values prior to the RDI. The average $E C_{1: 5}$ value of CK decreased by $24.82 \%$ during the flowering to fruit set stage (Figure 2a). After the recovery irrigation, the soil $E C_{1: 5}$ values of $\mathrm{LD}, \mathrm{MD}$, and $\mathrm{SD}$ decreased to $123.6 \mu \mathrm{s} / \mathrm{cm}, 166.23 \mu \mathrm{s} / \mathrm{cm}$, and $219.03 \mu \mathrm{s} / \mathrm{cm}$, respectively, on August 17. However, the $E C_{1: 5}$ values of $\mathrm{LD}, \mathrm{MD}$, and $\mathrm{SD}$ were still $43.54 \%, 93.04 \%$, and $154.36 \%$ higher than the CK during the same period, respectively (Figure 2a).

In the $20-40 \mathrm{~cm}$ soil layer, the average $E C_{1: 5}$ values of $\mathrm{LD}$, $\mathrm{MD}$, and SD were $278.67 \mu \mathrm{s} / \mathrm{cm}, 313.30 \mu \mathrm{s} / \mathrm{cm}$, and $433.73 \mu \mathrm{s} / \mathrm{cm}$, respectively, and the corresponding increases were $19.88 \%$, $39.88 \%$, and $100.69 \%$, respectively (Figure 2b). After the recovery irrigation, the average $E C_{1: 5}$ values of the $\mathrm{LD}, \mathrm{MD}$, and SD treatments declined to $233.05,264.33$, and $315.97 \mu \mathrm{s} / \mathrm{cm}$, respectively. This was an increase of $62.38 \%, 84.18 \%$, and $120.16 \%$, respectively, compared to the corresponding $E C_{1: 5}$ values at the flowering to fruit set stage prior to the application of RDI (Figure 2b).

In the $40-60 \mathrm{~cm}$ soil layer, the average $E C_{1: 5}$ values increased from $212.69 \mu \mathrm{s} / \mathrm{cm}, 187.49 \mu \mathrm{s} / \mathrm{cm}$, and $233.63 \mu \mathrm{s} / \mathrm{cm}$ (before RDI) 
to $230.68 \mu \mathrm{s} / \mathrm{cm}, 279.40 \mu \mathrm{s} / \mathrm{cm}$, and $393.70 \mu \mathrm{s} / \mathrm{cm}$ (after RDI) for $\mathrm{LD}, \mathrm{MD}$, and SD, respectively. This was an increase of $8.46 \%$, $49.02 \%$, and $68.51 \%$, respectively, compared with the original $E C_{1: 5}$ values (Figure $2 \mathrm{c}$ ). Subsequently, with irrigation levels the same as the control, the $E C_{1: 5}$ values of $\mathrm{LD}, \mathrm{MD}$, and $\mathrm{SD}$ were reduced to $207.23 \mu \mathrm{s} / \mathrm{cm}, 235.90 \mu \mathrm{s} / \mathrm{cm}$, and $293.82 \mu \mathrm{s} / \mathrm{cm}$, respectively, on August 17. This was a decrease of $10.16 \%$, $15.57 \%$, and $25.37 \%$, respectively, compared with the $E C_{1: 5}$ values of the corresponding treatments on July 29 (Figure 2c).
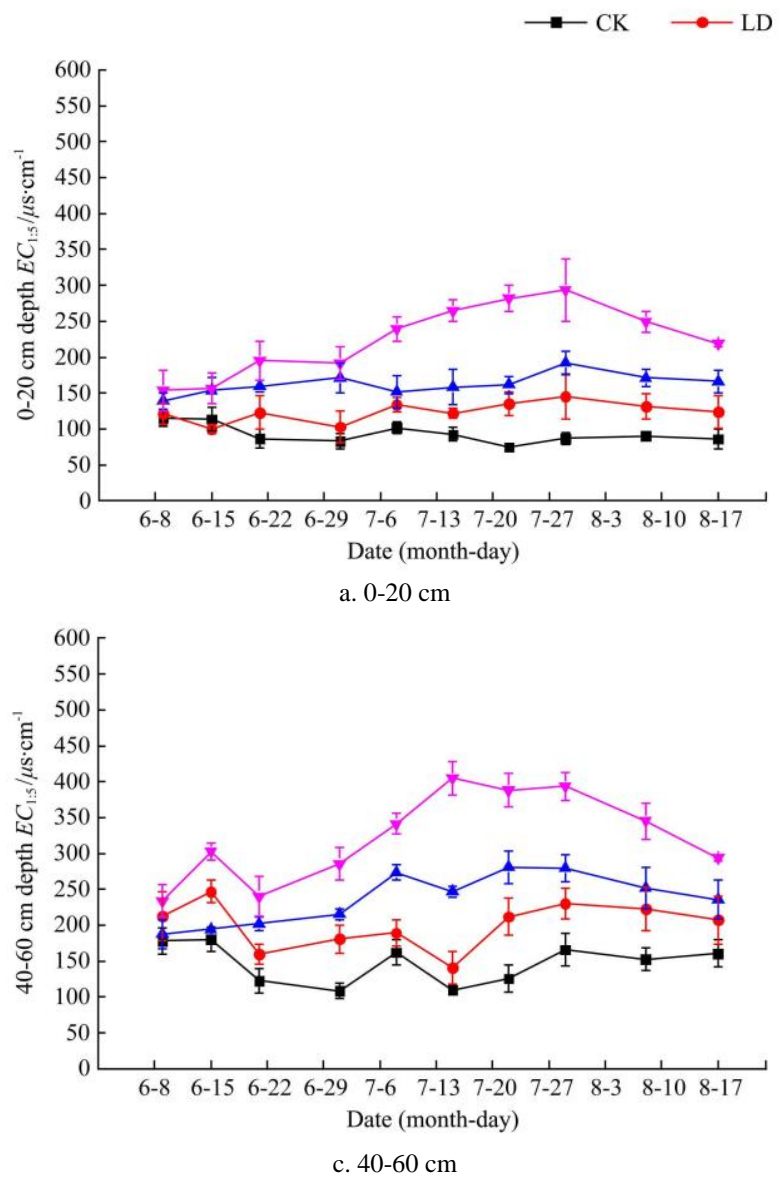

In the $60-80 \mathrm{~cm}$ soil layer, the average $E C_{1: 5}$ values of $\mathrm{LD}$, $\mathrm{MD}$, and SD increased to $278.10 \mu \mathrm{s} / \mathrm{cm}, 377.47 \mu \mathrm{s} / \mathrm{cm}$, and 471.00 $\mu \mathrm{s} / \mathrm{cm}$, respectively. This was an increase of $139.53 \%, 225.12 \%$, and $305.68 \%$, respectively, compared with the $E C_{1: 5}$ values without RDI (Figure 2d). The average $E C_{1: 5}$ values of $\mathrm{LD}, \mathrm{MD}$, and $\mathrm{SD}$ were reduced to $243.67 \mu \mathrm{s} / \mathrm{cm}, 323.33 \mu \mathrm{s} / \mathrm{cm}$, and $380.33 \mu \mathrm{s} / \mathrm{cm}$, respectively, after resuming irrigation. This was an increase of only $33.24 \%, 55.18 \%$, and $79.02 \%$, respectively, compared to the initial $E C_{1: 5}$ values (Figure 2d).
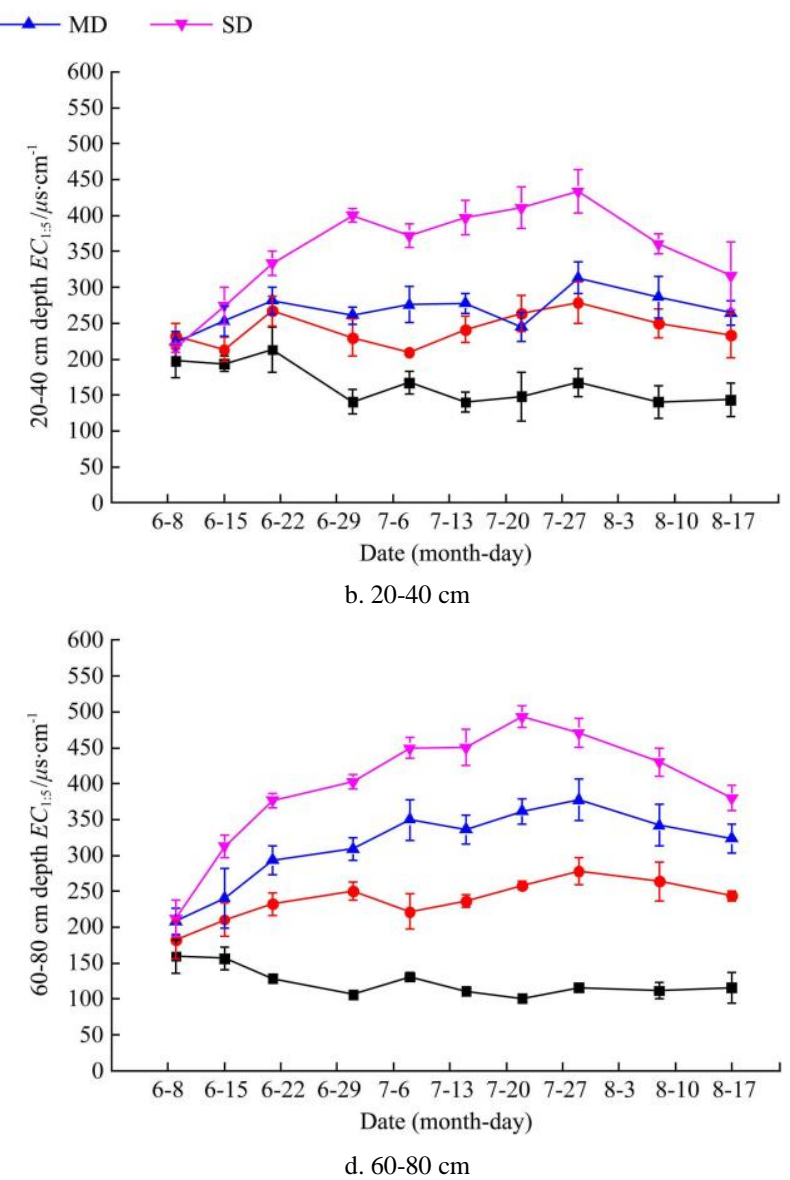

Note: Means are plotted \pm SE $(n=3)$. CK, LD, MD and SD stand for the different irrigation treatments (Table 3).

Figure 2 Change of the average $E C_{1: 5}$ values, under different regulated deficit treatments, at the depths of $0-20 \mathrm{~cm}(\mathrm{a}), 20-40 \mathrm{~cm}(\mathrm{~b})$, $40-60 \mathrm{~cm}(\mathrm{c})$ and $60-80 \mathrm{~cm}(\mathrm{~d})$.

3.2 Leaf photosynthetic rate, transpiration rate, stomatal conductance, and water use efficiency

The $P_{\mathrm{n}}, T_{\mathrm{r}}$, and $g_{\mathrm{s}}$ of the control continuously increased from early June to late July, stabilizing at above $14.5 \mu \mathrm{mol} \mathrm{CO} / 2 \mathrm{~m}^{2} \mathrm{~s}$ until the middle of August. A comparison among all plants revealed no significant differences for the leaf $P_{\mathrm{n}}, T_{\mathrm{r}}, g_{\mathrm{s}}$ or $W U E_{\mathrm{L}}$ before the RDI. The irrigation treatments at the flowering to fruit set stage had significant effects on the leaf $P_{\mathrm{n}}, T_{\mathrm{r}}, g_{\mathrm{s}}$, and $W U E_{\mathrm{L}}$ of the gray jujube tree (Figure $3 \mathrm{a}-\mathrm{d}$ ).

The $P_{\mathrm{n}}, T_{\mathrm{r}}$, and $g_{\mathrm{s}}$ of the LD, MD and SD treatments declined after the RDI, with a larger water deficit causing $P_{\mathrm{n}}, T_{\mathrm{r}}$, and $g_{\mathrm{s}}$ to reduce further. However, the $W U E_{\mathrm{L}}$ of $\mathrm{MD}$ and $\mathrm{SD}$ was significantly higher than that of the control. In late July, the $P_{\mathrm{n}}$ of the LD, MD and SD treatments was $9.41 \%, 41.27 \%$, and $45.45 \%$ lower than CK, respectively (Figure 3a). Additionally, the $T_{\mathrm{r}}$ of the $\mathrm{LD}, \mathrm{MD}$, and SD treatments was $9.37 \%, 47.37$, and $54.36 \%$ lower than CK, respectively (Figure 3b). However, the average $W U E_{\mathrm{L}}$ values of $\mathrm{LD}, \mathrm{MD}$ and $\mathrm{SD}$ were $0.19 \%, 13.39 \%$, and $19.18 \%$ higher than CK, respectively on July 22 (Figure 3d). The $g_{\mathrm{s}}$ of LD, MD and SD was $16.16 \%, 44.94 \%$, and $52.06 \%$ lower than that of CK, respectively (Figure 3c).

After the recovery irrigation, the $P_{\mathrm{n}}, T_{\mathrm{r}}$, and $g_{\mathrm{s}}$ of the water stress treatments increased sharply, and the $P_{\mathrm{n}}$, and $g_{\mathrm{s}}$ of the MD treatment exceeded those of the control. Compared to the period before the recovery, the $P_{\mathrm{n}}$ of LD, MD and SD increased by $7.32 \%$, $39.33 \%$, and $33.40 \%$, respectively by August 8 , and then increased by a further $6.89 \%, 87.75 \%$, and $65.25 \%$, respectively by August 17 (Figure 3a). Additionally, the $T_{\mathrm{r}}$ of LD, MD and SD increased by $6.25 \%, 49.60 \%$, and $40.14 \%$, respectively by August 8 , and then increased by a further $10.85 \%, 91.84 \%$ and $95.10 \%$, respectively by August 17 (Figure 3b). The LD, MD, and SD treatments had a lower $g_{\mathrm{s}}$, decreasing from $16.16 \%, 44.94 \%$ and $52.06 \%$ to $-0.67 \%$, $-9.86 \%$ and $3.32 \%$, respectively compared with the control (Figure $3 \mathrm{c})$. The $P_{\mathrm{n},} g_{\mathrm{s}}$, and $W U E_{\mathrm{L}}$ of MD were $13.48 \%, 1.44 \%$, and $11.79 \%$ higher, respectively, than that of CK on 17 August (Figure 3a, c, d). However, this phenomenon was not found in LD and $\mathrm{SD}$, with the $P_{\mathrm{n}}, T_{\mathrm{r}}$ and $g_{\mathrm{s}}$ exhibited no significant differences among these treatments and the control. On the whole, the response of the $T_{\mathrm{r}}$ and $g_{\mathrm{s}}$ to the RDI had a similar trend to that of the $P_{\mathrm{n}}$ in all water deficit treatments (Figure 3a-c). 


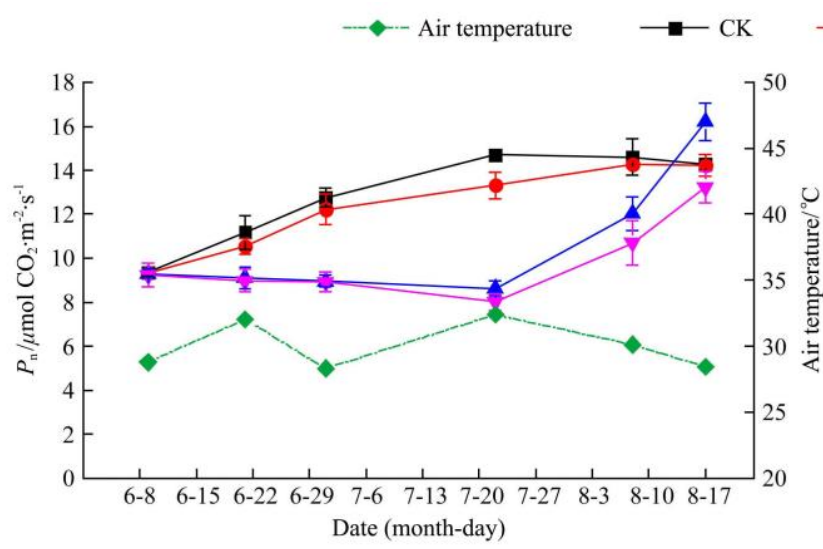

a. $P_{\mathrm{n}}$

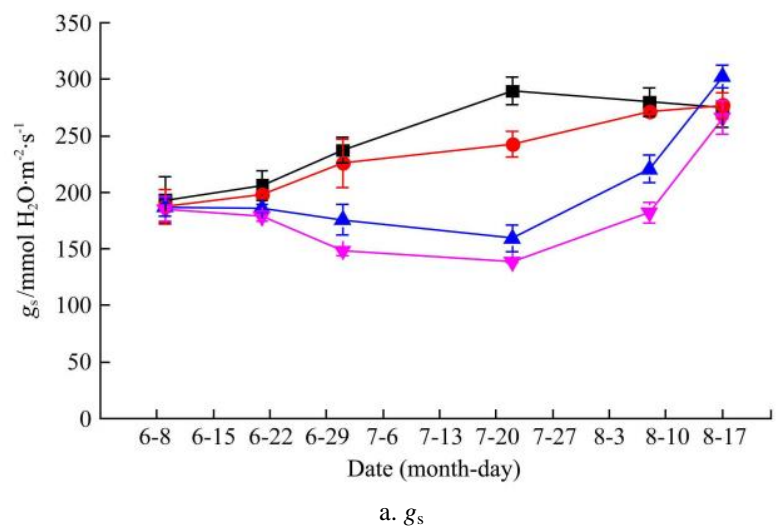

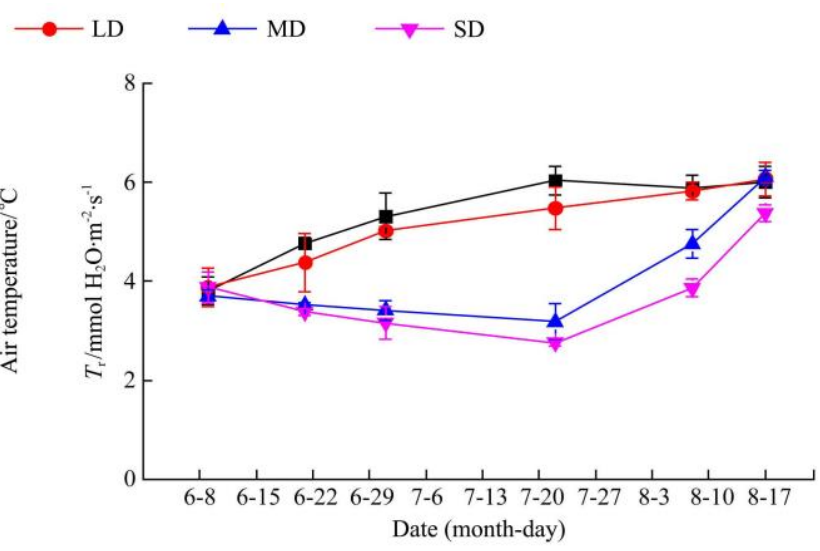

b. $T_{\mathrm{r}}$

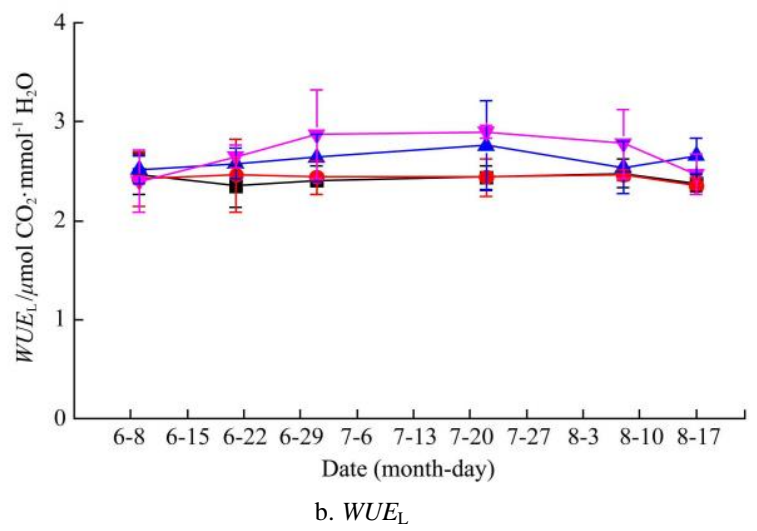

Note: Means are plotted \pm SE $(n=3)$. CK, LD, MD and SD stand for the different irrigation treatments (Table 2).

Figure 3 Changes in the leaf photosynthetic rate $P_{\mathrm{n}}(\mathrm{a})$, transpiration rate $T_{\mathrm{r}}(\mathrm{b})$, stomatal conductance $g_{\mathrm{s}}$ (c) and water use efficiency $W U E_{\mathrm{L}}(\mathrm{d})$ of gray jujube trees under different deficit treatments

\subsection{Yield and fruit quality}

The fruit quality, in terms of the soluble solid content, soluble sugar, single fruit weight and sugar/acid ratio, was significantly increased under LD, MD, and SD compared to control. The VC was also enhanced, however, no significant difference was observed between the treatments. As shown in Table 4, the results indicated that the yields of the LD and MD treatments were significantly increased, while the yield of SD represented a slight decline with no significant difference compared to the control.

The average VC and single fruit weight of LD, MD and SD were $2.59 \%, 3.70 \%, 8.89 \%$, and $9.17 \%, 17.43 \%, 18.96 \%$ higher than that of the control, respectively. Additionally, the soluble sugar content was increased by $5.67 \%, 12.00 \%$ and $9.72 \%$, respectively (Table 4). However, water stress significantly reduced the organic acid by $9.86 \%, 15.49 \%$, and $22.54 \%$, respectively, compared with the control. Therefore, the sugar/acid ratios of the $\mathrm{LD}, \mathrm{MD}$ and $\mathrm{SD}$ treatments increased to 101.23, 114.89 and 121.39, respectively, which clearly exceeded the control treatment value of 86.50 (Table 4). Moreover, compared with the control, the yield and soluble solid content of the LD and MD treatments were significantly increased by $3.21 \%, 9.57 \%$ and $10.19 \%, 25.48 \%$ (Table 4), respectively, while those of the SD treatment were similar to that of CK.

Table 4 Effects of the regulated deficit treatments on the yield and fruit quality of gray jujube trees

\begin{tabular}{|c|c|c|c|c|c|c|c|}
\hline Treatment & Yield $/ \mathrm{kg} \cdot \mathrm{hm}^{-2}$ & Soluble solid $/ \%$ & Soluble sugar/\% & Organic acid $/ \%$ & Vitamin C (VC)/mg $\cdot(100 \mathrm{~g})^{-1}$ & Single fruit weight/g & $\begin{array}{c}\text { Sugar-acid ratio } \\
1 \%\end{array}$ \\
\hline CK & $7485 \mathrm{a}$ & $31.4 \mathrm{a}$ & $61.7 \mathrm{a}$ & $0.71 b$ & $27.0 \mathrm{a}$ & $3.27 \mathrm{a}$ & $86.50 \mathrm{a}$ \\
\hline $\mathrm{LD}$ & $7725 \mathrm{ab}$ & $34.6 \mathrm{~b}$ & $65.2 \mathrm{ab}$ & $0.64 \mathrm{ab}$ & $27.7 \mathrm{a}$ & $3.57 \mathrm{~b}$ & $101.23 b$ \\
\hline MD & $8202 b$ & $39.4 \mathrm{c}$ & $69.1 b$ & $0.60 \mathrm{a}$ & $28.0 \mathrm{a}$ & $3.84 \mathrm{bc}$ & $114.89 \mathrm{c}$ \\
\hline SD & $7327 a$ & $32.7 \mathrm{ab}$ & $67.7 \mathrm{~b}$ & $0.55 \mathrm{a}$ & $29.4 \mathrm{a}$ & $3.89 \mathrm{c}$ & $121.39 \mathrm{c}$ \\
\hline
\end{tabular}

Note: Values are the means of 3 replicates, those followed by different small letters in the same column are significantly different at the $p=0.05$ level of probability.

\section{Discussion}

\subsection{Soil salinity}

The considerably high evapotranspiration rate and comparatively low leaching fraction were likely the primary causes of the enhanced soil salinity in the deficit irrigation treatments under desert conditions. Thus, the $E C_{1: 5}$ values of $\mathrm{LD}, \mathrm{MD}$ and SD among all the soil layers $(0-20 \mathrm{~cm}, 20-40 \mathrm{~cm}, 40-60 \mathrm{~cm}$ and $60-80 \mathrm{~cm}$ ) were significantly increased with the more severe deficit irrigation treatments resulting in higher $E C_{1: 5}$ values. Similar results were found in other studies ${ }^{[31,35]}$. As reported by Aragüés et al. ${ }^{[32]}$, severe deficit irrigation treatments in grapevine and peach orchards led to high mean soil salinization rates, indicating that long periods of applying a deficit irrigation strategy would have an adverse effect on the soil salinity control. After the recovery irrigation, the $E C_{1: 5}$ values of $\mathrm{LD}, \mathrm{MD}$ and $\mathrm{SD}$ rapidly declined, which was correlated with the degree of the RDI. However, these values are still higher than those of CK. Sarwar and 
Bastiaanssen $^{[33]}$ showed that one water conservation strategy is sufficient to maintain a reasonably high relative transpiration rate, while saving up to $25 \%$ of irrigation water and maintaining the salt storage change and salinity hazard index within acceptable limits. Similar results were found by other researchers ${ }^{[30,36]}$. Moreover, the $E C_{1: 5}$ values of the $60-80 \mathrm{~cm}$ soil layer were higher than those of other depths in the same treatment. The ratio of drainage to irrigation, used to evaluate the salt mass balance in a plain oasis irrigation district in an arid area, is related to the volume and salt content of irrigation and drainage water ${ }^{[37]}$. These results implied an extremely important fact that the water deficit is balanced with the leaching fraction for various reasons, including the response and sensitivity of crops to water stress, increase of soil salinization, and conservation of the irrigation water with deficit irrigation.

\subsection{Leaf physiological parameters of gray jujube trees}

Stomatal closing of the gray jujube is one of the most important physiological responses to water stress during the flowering to fruit set stage, as it reduces the water lost through transpiration ${ }^{[38,39]}$. This physiological response reduces the influx of $\mathrm{CO}_{2}$ and is the significant factor responsible for the decline in the $P_{\mathrm{n}}{ }^{[27,40]}$. Therefore, $T_{\mathrm{r}}$ and $g_{\mathrm{s}}$ immediately declined to reduce the water loss caused by water stress and reduced $P_{\mathrm{n}}^{[28,29,41]}$. Similar results of declines in photosynthesis parameters were also shown in the papaya ${ }^{[27]}$, pear ${ }^{[26]}$, olive ${ }^{[41]}$, pear-jujube ${ }^{[8]}$ and kumquat ${ }^{[39]}$.

This study revealed that slight water deficit has no significant effect on the $P_{\mathrm{n}}, T_{\mathrm{r}}$ and $g_{\mathrm{s}}$. However, these sharply declined following the increase in the degree of the water deficit. Similar results were also found in the study of Cui et al. ${ }^{[22]}$ In addition, the variation in the $P_{\mathrm{n}}$ was slightly more than the change of the $T_{\mathrm{r}}$ (Figures $2 \mathrm{a}$ and $2 \mathrm{~b}$ ), which significantly increased the water use efficiency as the water deficit increased. This result also appeared in the studies on the pear-jujube ${ }^{[22,42]}$, olive ${ }^{[41]}$ and pear ${ }^{[26]}$. After the recovery irrigation, the $T_{\mathrm{r}}$ of the treatments that had experienced a water deficit was still lower than that of the control, while the $P_{\mathrm{n}}$ of the treatments had no significant difference compared with the control. Therefore, the recovery irrigation induced substantial improvement of the $W U E_{\mathrm{L}}$, with similar results found in quantity research studies ${ }^{[22]}$. In contrast, Zhao et al. ${ }^{[26]}$ indicated that the relative humidity remained low and is responsible for the consistent variation of the $P_{\mathrm{n}}, T_{\mathrm{r}}$ and $g_{\mathrm{s}}$.

This study found that the $P_{\mathrm{n}}, T_{\mathrm{r}}$, and $g_{\mathrm{s}}$ of the MD treatment recovered to the level of those in the control significantly earlier than the SD treatment after the resumption of irrigation. After re-watering for 3 days, the average $P_{\mathrm{n}}$ of the SD, MD and LD treatments at different growth stages changed by $-13.2 \%, 1.1 \%$ and $11.6 \%$, respectively, in pear-jujube trees ${ }^{[22]}$. The leaf physiological parameters of the treatments irrigated with $60 \%$ of $E_{\mathrm{p}}$ in cell division and slow fruit enlargement stage on pear trees required 1 to 2 weeks to restore to the levels of the control after the resumption of irrigation. Whereas, the treatments irrigated with $40 \%$ of $E_{\mathrm{p}}$ in cell division and slow fruit enlargement stage needed 3 to 4 weeks to restore ${ }^{[26]}$. This result revealed that the speed of recovery in the deficit treatment was negatively related to the degree of water stress. Cui et al. ${ }^{[22]}$, Zhao et al. ${ }^{[26]}$, Pérez-Pérez et al. ${ }^{[25]}$ and Kang et al. ${ }^{[16]}$ had similar results with the pear-jujube, pear, citrus and maize, respectively. In this study, the recovery time of the $P_{\mathrm{n}}, T_{\mathrm{r}}$, and $g_{\mathrm{s}}$ of the deficit treatments were at least two weeks.

After the recovery irrigation, the $P_{\mathrm{n}}, T_{\mathrm{r}}$, and $g_{\mathrm{s}}$ of MD sharply increased, exceeding those of the control on August 22. Zhao et al. ${ }^{[26]}$ indicated that the $P_{\mathrm{n}}$ of the S-1 treatments increased by $11 \%$ and $14 \%$ compared with the control, and reached their highest values by the end of July in 2009 and 2010, respectively. The $P_{\mathrm{n}}$, $T_{\mathrm{r}}$, and $g_{\mathrm{s}}$ of the deficit irrigation treatments increased significantly in 2003, surpassing the control values after recovery irrigation for $50 \mathrm{~d}^{[25]}$. This phenomenon was also observed by Cui et al. ${ }^{[22]}$ in pear-jujube trees. Moreover, the $W U E_{\mathrm{L}}$ was consistently significantly higher than that of the control after the irrigation resumed $^{[22]}$

\subsection{Yield and fruit quality}

The RDI at the flowering to fruit set stage evidently improved the gray jujube fruit quality, indicating that the deficit irrigation was beneficial. Furthermore, the yields of the LD and MD treatments significantly increased and were higher than that of CK. There were no obvious differences in yield between the SD and CK treatments, indicating that a moderate water deficit does not have any possible adverse impacts on the gray jujube production in desert conditions. Similar results were found by other researchers on potato ${ }^{[43]}$, tomato ${ }^{[44,45]}$ and cotton ${ }^{[46]}$.

Deficit irrigation may lead to photosynthetic products being distributed to the fruits, thus enhancing the soluble solid content and sugar/acid ratio ${ }^{[14,24,47]}$, which was also found in this study. This might be because the deficit irrigation inhibited the vegetative growth, causing the photosynthetic products and nutritional substances in the leaves and branches being transferred to the fruit organs ${ }^{[8]}$. The enhanced VC content in the deficit treatments has been observed in other crops, such as the tomato ${ }^{[12,45]}$ and pear-jujube ${ }^{[8]}$. Wu et al ${ }^{[14]}$ revealed that the soluble sugar contents of the deficit treatment significantly improved in both 2009 and 2010 , which aligns with the results of this study. Moreover, Cui et al. ${ }^{[8]}$ reported that water deficit reduced the organic acid content of pear-jujube trees, which agrees with the results of this research. In contrast, $\mathrm{Ma}$ et al. ${ }^{[24]}$ indicated that severe water stress improved the organic acids in the pear-jujube at the fruit maturation stage. $\mathrm{Wu}$ et al. ${ }^{[14]}$ showed over two years that the titratable acid content had no discernible differences among different deficit treatments. The present research confirmed that RDI could increase the gray jujube fruit quality and yield. However, how water-deficiency affects the organic acids of the gray jujube needs to be further investigated.

\section{Conclusions}

There were signs that the RDI had improved the soil salinity because of the considerably high evapotranspiration and comparatively low irrigation amount. However, the high soil salinity caused by the RDI declined sharply after the commencement of the recovery irrigation. The deficit irrigation reduced the stomatal conductance, photosynthetic rate and transpiration rate, but significantly enhanced the leaf water use efficiency, at the flowering to fruit set stage of the gray jujube. The water stress may lead to a compensatory effect because of the photosynthetic products being distributed to the fruits rather than physiological growth. After the recovery irrigation, the $P_{\mathrm{n}}$ of the deficit irrigation treatments had significantly increased, which is beneficial for improving the yield and fruit quality of the gray jujube. Compared with CK, the moderate RDI enhanced the yield by $9.57 \%$ and improved the single fruit weight, sugar/acid ratio and $W U E_{\mathrm{L}}$. Additionally, $30 \%$ of the water consumption was conserved at the flowering to fruit set stage. Therefore, decreasing irrigation water use did not interfere with controlling soil salinity and improving the yield and fruit quality. However, 
this study only investigated the RDI effects at the flowering to fruit set stage of the gray jujube and have not involved the RDI effects at different growth stages. Therefore, future research is required in this aspect.

\section{Acknowledgements}

This study was funded by the National Key Research Program (2016YFC0400208) and Technical Demonstration Project of Ministry of Water Resources (SF-201733).

\section{[References]}

[1] Ding S, Wang R, Shan Y, Li G, Ou S. Changes in pectin characteristics during the ripening of jujube fruit. Journal of the Science of Food and Agriculture, 2017; 97(12): 4151-4159.

[2] Gao Q, Wu C, Wang M. The jujube (Ziziphus jujuba mill.) fruit: A review of current knowledge of fruit composition and health benefits. Journal of Agricultural and Food Chemistry, 2013; 61(14): 3351-3363.

[3] Li H, Li F, Wang L, Sheng J, Xin Z, Zhao L,et al. Effect of nano-packing on preservation quality of Chinese jujube (Ziziphus jujuba Mill. Var. Inermis (Bunge) Rehd). Food Chemistry, 2009; 114(2): 547-552.

[4] Li J, Fan L, Ding S, Ding X. Nutritional composition of five cultivars of chinese jujube. Food Chemistry, 2007; 103(2): 454-460.

[5] Zhang H, Jiang L, Ye S, Ye Y, Ren F. Systematic evaluation of antioxidant capacities of the ethanolic extract of different tissues of jujube (Ziziphus jujuba Mill.) from China. Food and Chemical Toxicology, 2010; 48(6): 1461-1465.

[6] Liu H G, He X L, Li J, Li F, Gong P, Zhang J, et al. Effects of water-fertilizer coupling on root distribution and yield of Chinese Jujube trees in Xinjiang. International Journal of Agricultural and Biological Engineering, 2017; 10(6): 103-114.

[7] Statistic Bureau of Xinjiang Uygur Autonomous Region. Xinjiang Statistical Yearbook, 2016. Beijing: China Statistics Press; 2016.

[8] Cui N, Du T, Kang S, Li F, Zhang J, Wang M, Li Z. Regulated deficit irrigation improved fruit quality and water use efficiency of pear-jujube trees. Agricultural Water Management, 2008; 95(4): 489-497.

[9] English M. Deficit irrigation. I: Analytical framework. Journal of Irrigation and Drainage Engineering, 1990; 116(3): 399-412.

[10] Pereira L S, Oweis T, Zairi A. Irrigation management under water scarcity. Agricultural Water Management, 2002; 57(3): 175-206.

[11] El-Mageed T A A, Semida W M, El-Wahed M H A. Effect of mulching on plant water status, soil salinity and yield of squash under summer-fall deficit irrigation in salt affected soil. Agricultural Water Management, 2016; 173: $1-12$.

[12] Akhtar S S, Li G, Andersen M N, Liu F. Biochar enhances yield and quality of tomato under reduced irrigation. Agricultural Water Management, 2014; 138: 37-44.

[13] Chaves M M, Santos T P, Souza C R, Ortuño M F, Rodrigues M L, Lopes C $\mathrm{M}$, et al. Deficit irrigation in grapevine improves water-use efficiency while controlling vigour and production quality. Annals of Applied Biology, 2007; 150(2): 237-252.

[14] Wu Y, Zhao Z, Wang W, Ma Y, Huang X. Yield and growth of mature pear trees under water deficit during slow fruit growth stages in sparse planting orchard. Scientia Horticulturae, 2013; 164: 189-195.

[15] Zarco-Tejada P J, González-Dugo V, Berni J A J. Fluorescence, temperature and narrow-band indices acquired from a UAV platform for water stress detection using a micro-hyperspectral imager and a thermal camera. Remote Sensing of Environment, 2012; 117: 322-337.

[16] Kang S, Shi W, Zhang J. An improved water-use efficiency for maize grown under regulated deficit irrigation. Field Crops Research, 2000; 67(3): 207-214

[17] Girona J, Mata M, Marsal J. Regulated deficit irrigation during the kernel-filling period and optimal irrigation rates in almond. Agricultural Water Management, 2005; 75(2): 152-167.

[18] Medrano H, Tomás M, Martorell S, Escalona J, Pou A, Fuentes S, et al. Improving water use efficiency of vineyards in semi-arid regions. A review. Agronomy for Sustainable Development, 2015; 35(2): 499-517.

[19] Geerts S, Raes D. Deficit irrigation as an on-farm strategy to maximize crop water productivity in dry areas. Agricultural Water Management, 2009; 96(9): 1275-1284.

[20] Fereres E, Soriano M A. Deficit irrigation for reducing agricultural water use. Journal of Experimental Botany, 2006; 58(2): 147-159.

[21] Costa J M, Ortuño M F, Chaves M M. Deficit irrigation as a strategy to save water: Physiology and potential application to horticulture. Journal of Integrative Plant Biology, 2007; 49(10): 1421-1434.

[22] Cui N, Du T, Li F, Tong L, Kang S, Wang M, et al. Response of vegetative growth and fruit development to regulated deficit irrigation at different growth stages of pear-jujube tree. Agricultural Water Management, 2009; 96(8): 1237-1246.

[23] Galindo A, Cruz Z N, Rodríguez P, Collado-González J, Corell M, Memmi $\mathrm{H}$, et al. Jujube fruit water relations at fruit maturation in response to water deficits. Agricultural Water Management, 2016; 164: 110-117.

[24] Ma F, Kang S, Wang M, Pang X, Wang J, Li Z. Effect of regulated deficit irrigation on water use efficiency and fruit quality of pear-jujube tree in greenhouse. Trans of the CSAE, 2006; 22(1): 37-43. (in Chinese)

[25] Pérez-Pérez J G, Romero P, Navarro J M, Botía P. Response of sweet orange cv 'Lane late' to deficit irrigation in two rootstocks. I: Water relations, leaf gas exchange and vegetative growth. Irrigation Science, 2008; 26(5): 415-425.

[26] Zhao Z, Wang W, Wu Y, Xu M, Huang X, Ma Y, Ren D. Leaf physiological responses of mature pear trees to regulated deficit irrigation in field conditions under desert climate. Scientia Horticulturae, 2015; 187: $122-130$.

[27] de Lima R S N, de Assis Figueiredo F A M M, Martins A O, de Deus B C D S, Ferraz T M, Gomes M D M D, et al. Partial rootzone drying (PRD) and regulated deficit irrigation (RDI) effects on stomatal conductance, growth, photosynthetic capacity, and water-use efficiency of papaya. Scientia Horticulturae, 2015; 183: 13-22.

[28] Massacci A, Nabiev S M, Pietrosanti L, Nematov S K, Chernikova T N, Thor K, et al. Response of the photosynthetic apparatus of cotton (Gossypium hirsutum) to the onset of drought stress under field conditions studied by gas-exchange analysis and chlorophyll fluorescence imaging. Plant Physiology and Biochemistry, 2008; 46(2): 189-195.

[29] Schroeder J I, Kwak J M, Allen G J. Guard cell abscisic acid signalling and engineering drought hardiness in plants. Nature, 2001; 410(6826): 327-330.

[30] Aragüés R, Medina E T, Martínez-Cob A, Faci J. Effects of deficit irrigation strategies on soil salinization and sodification in a semiarid drip-irrigated peach orchard. Agricultural Water Management, 2014; 142: $1-9$.

[31] Mounzer O, Pedrero-Salcedo F, Nortes P A, Bayona J, Nicolás-Nicolás E Alarcón J J. Transient soil salinity under the combined effect of reclaimed water and regulated deficit drip irrigation of Mandarin trees. Agricultural Water Management, 2013; 120: 23-29.

[32] Aragüés R, Medina ET, Zribi W, Clavería I, Álvaro-Fuentes J, Faci J. Soil salinization as a threat to the sustainability of deficit irrigation under present and expected climate change scenarios. Irrigation Science, 2015; 33(1): 67-79.

[33] Sarwar A, Bastiaanssen W G M. Long-term effects of irrigation water conservation on crop production and environment in semiarid areas. Journal of Irrigation \& Drainage Engineering, 2001; 127(6): 331-338.

[34] Pérez-Pastor A, Ruiz-Sánchez M C, Domingo R. Effects of timing and intensity of deficit irrigation on vegetative and fruit growth of apricot trees. Agricultural Water Management, 2014; 134: 110-118.

[35] Bourgault M, Madramootoo C A, Webber H A, Stulina G, Horst M G, Smith D L. Effects of deficit irrigation and salinity stress on common bean (Phaseolus Vulgaris L.) and mungbean (Vigna Radiata L. Wilczek) grown in a controlled environment. Journal of Agronomy and Crop Science, 2010 196(4): 262-272.

[36] Intrigliolo D S, Castel J R. Long-term effects of deficit irrigation and subsequent recovery of young Japanese plum trees. Acta Horticulturae, 2011; 889: 241-248.

[37] Hu S, Zhao C, Zhu H. Hydrosalinity balance and critical ratio of drainage t o irrigation (RDI) for salt balance in Weigan River irrigation district of the Tarim basin (China). Environmental Earth Sciences, 2017; 76(6)

[38] Chai Q, Gan Y, Zhao C, Xu H, Waskom R M, Niu Y, et al. Regulated deficit irrigation for crop production under drought stress. A review. Agronomy for Sustainable Development, 2016; 36(1): 3.

[39] Chang Y, Chang Y, Lin L. Response of shoot growth, photosynthetic capacity, flowering, and fruiting of potted 'Nagami' kumquat to different regulated deficit irrigation. Horticulture, Environment, and Biotechnology, 2015; 56(4): 444-454.

[40] Su P, Liu X. Photosynthetic characteristics of linze jujube in conditions of high temperature and irradiation. Scientia Horticulturae, 2005; 104(3): 
339-350.

[41] Giorio P, Sorrentino G, d'Andria R. Stomatal behaviour, leaf water status and photosynthetic response in field-grown olive trees under water deficit. Environmental and Experimental Botany, 1999; 42(2): 95-104.

[42] Ma F, Kang S, Li F, Zhang J, Du T, Hu X, et al. Effect of water deficit in different growth stages on stem sap flux of greenhouse grown pear-jujube tree. Agricultural Water Management, 2007; 90(3): 190-196.

[43] Shahnazari A, Liu F, Andersen M N, Jacobsen S, Jensen C R. Effects of partial root-zone drying on yield, tuber size and water use efficiency in potato under field conditions. Field Crops Research, 2007; 100(1): 117-124.

[44] Sánchez-Rodríguez E, Leyva R, Constán-Aguilar C, Romero L, Ruiz J M.
Grafting under water stress in tomato cherry: Improving the fruit yield and quality. Annals of Applied Biology, 2012; 161(3): 302-312.

[45] Sun Y, Feng H, Liu F. Comparative effect of partial root-zone drying and deficit irrigation on incidence of blossom-end rot in tomato under varied calcium rates. Journal of Experimental Botany, 2013; 64(7): 2107-2116.

[46] Du T, Kang S, Zhang J, Li F, Hu X. Yield and physiological responses of cotton to partial root-zone irrigation in the oasis field of northwest China. Agricultural Water Management, 2006; 84(1-2): 41-52.

[47] Hutton R J, Loveys B R. A partial root zone drying irrigation strategy for citrus-Effects on water use efficiency and fruit characteristics. Agricultural Water Management, 2011; 98(10): 1485-1496. 